\title{
The Role of RFID in Agro-Food Sector
}

\author{
Vivek Kumar* and Anjali Srivastava \\ Harcourt Butler Technical University, India
}

Submission: November 23, 2017; Published: March 12, 2018

*Corresponding author: Vivek Kumar, Harcourt Butler Technical University, Kanpur, India, Email: viveksachan99@rediffmail.com

\begin{abstract}
In the agri-food sector, safety of the product is a major concern in several countries, in particular, the traceability of agri-food products which is mandatory by law. Radio Frequency Identification (RFID) is a technology which helps to improve the management of information flow within the supply chain and security in the agri-food sector. RFID is already being used for years in animal identification and tracking and in the food chain for traceability control. The development of RFID sensors tags has improved monitoring of the cold chain of perishable food products, environmental monitoring, irrigation, specialty crops and farm machinery. However, major applications of RFID technologies are still limited. Thus, this review provides the comprehensive overview on the current developments of RFID technology within the agri-food industry and at the same time discussing its potential in technological and logistical development in different sectors of the production/distribution chain. This review facilitates a quick content analysis for readers indentifying future research direction of RFID technology in the agri-food sector with an overview of opportunities and constraints for the wide adoption of RFID.
\end{abstract}

Keywords: RFID; Agriculture; Food; Traceability; Sensor

\section{Introduction}

As the world continues to evolve, demand for profitability and expediency increases. India being an agro-based country and hence; with a great diversity of products, which is influenced by a number of factors like weather conditions and spread of diseases or pests during agriculture production, deterioration of fresh produce during post-harvest handling, geographical distances between areas of production and areas of consumption etc.; it is very difficult to keep this sector safe. It is also difficult to maintain safer food supply by coordinating tracking of product from suppliers and facilitate traceability from supplier to customer in the market. The quick access of the broadest set data related to food safety or quality issuesis highly critical. Recent technological developments in the area of networking devices, sensors and communication technology play significant role in sustainability of agro-food sector and getting the right product to the customer when they need. Wireless sensors and sensor networks applied in agriculture and food production for safety, traceability systems, environmental monitoring, precision agriculture, machine and process control etc. to achieve the target of proper tracking from 'farm to fork' [1].

Radio frequency identification (RFID) technology is one of such pervasive technology which is now increasingly utilized in food logistics, supply chain management, cold chain monitoring and retail [2]. RFID shows several advantages over traditional technologies like barcode and data loggers. RFID devices are more accurate and do not require visual contact [3]. It provides real-time information that can help retailer and distributor for product delivery schedule and allows customers to identify interior information of food product during supply chain. It can also improve accountability by implementing metric setting and tracking for individual warehouses, departments and processes. The first applications were developed just for identification; however, growing interest in other possible applications has led to the development of a new range RFID devices outfitted with sensors $[4,5]$. The aim of this paper is to review the numerous applications of RFID in the food and agriculture field, its advantages over conventional methods as well as its future aspects in this particular sector.

\section{Basics of Rfid}

This technology was first used for identification of military aircraft whether it is a friend or foe systems during the Second World War. Main components of a RFID system are categorized in three parts: (i) Tag (used to store the information), (ii) Reader or interrogator (used to collect the information stored in a tag) (iii)Software (used to manage the received data and operations of reader and tag) [6]. Generally RFID tags are classified as passive, semi-passive and active tags. Commercial active and semi-passive tags are used to collect temperature information [7]. Other semi-passive tags outfitted with sensor are under development, like humidity and light [3], shock/vibration [8], pH [9] and concentration of gases, such as acetaldehyde or ethylene [10]. Biosensor tags are also being investigatedfor detecting 
bacterial contamination on food products along the supply chain [11].

\section{Role of Rfid in Agriculture Sector}

RFID technology has been successfully tested in agriculture for environmental monitoring, irrigation, specialty crops and farm machinery, fruit harvesting and packaging [2,12]. This technology also plays an important role in cattle and poultry farming. Tagging of animals like cows, sheep, pigs, hen etc. allows the farmer to have superior traceability, better breeding control and data collection about each and every animal of the herd. Data collection in greenhouses is also possible with specialized RFID tags and readers, specially designed for the warm and humid conditions. Growth time, moisture content, equipment management and even personnel management and also in access control for the employees and their working time can also be managed with the help of this technology. RFID can also keep tabs on illegal fishing and marine animals. They are tagged with the fish box which helps to assess catch date, location of catch, size and quality, right there on the boat. The major role of this technology in the following area of agriculture field is:

\section{Traceability and safety of the livestock}

RFID is the earliest technology used for data recording and management of livestock. Implanting livestock with a RFIDenhanced microchip or ear tag would not only enable instant identification but also preserve a wide array of individual information such as body type, growth development, breeding lineage and lactation quality. RFID therefore enables the recording and tracking of individual animals over their entire lifecycle $[13,14]$. RFID usage helps to monitor health of the herd, keep individual medication and vaccination records, and prevent the spread of disease by tracking and segregating infected livestock at early stages, leading to successful isolation and treatment that saves the rest of the herd and maintain the quality of respective animal meat [15]. Therefore, RFID helps to improve farm management through increased efficiencies, reduced feed and labor costs, enhanced output and improved herd health.

\section{Production and processing}

RFID tag records information such as humidity, light, wind speed and rainfall during plantation and cultivation. By placing RFID tags into collar, card, injection, pill or just on agricultural products' packages and determined the healthy condition of the product [16]. It is convenient for processing enterprises to simultaneously add information on the tag, such as enterprises code, processing date, processing batch, and package weight, etc. used in processing $[17,18]$. Therefore, the continuity of agricultural product information can be successfully kept along with supply chain.

\section{Transportation}

RFID combined with GPS, real-time supervision and tracking service can be available for agricultural product logistics system. For the owners, they can find out the track of their goods via the computer network. For the check officers, goods can be examined only through tag so as to speed up the inspection. Meanwhile, by reading the information stored in RFID tag, it could be decided whether the temperature-shift will do harm to fresh agricultural product or not. RFID can also be used to monitor climacteric conditions during transport [10]. It is used for detection of unauthorized openings of shipments on the way of transportation [19].

\section{Storage, distribution and sales}

Before agricultural products enter warehouse, the data stored in RFID tag can directly be transmitted to computer. The computer will emit the warehousing instruction to the suitable rack and slots. Furthermore, the correct inventory pattern can be chosen depending on the product specification and requirement. The logistics information system of agricultural product will generate the picking and slotting task as soon as it receives the customer's order. The operator could pick out the right product immediately according to the information on the RFID tag. Extra information such as distribution vehicle, distribution route, schedule, etc. has been enriched in the RFID tag during the distribution process. Not only the vendors but also the consumers can benefit from RFID application in sales. The vendors can supervise the validity of commodities with the help of RFID tag especially for perishable products. On the other hand, consumers could gain the basic information along the supply chain from the origin to the destination. RFID can help consumers to ensure the agriculture products' safety. Therefore, the use of RFID in the whole agricultural products logistics system will help to promote the development of seamless exchanging, reading, writing for agricultural products information [20].

\section{Plants health management}

RFID can be usedfor plant health management, in particular for plant health inspection and certification, agrochemical management and their impact assessment [21,22]. Radiofrequency identification could help to reduce the spread of plant pathogens. RFID has been inserted in many plants for different purposes like in Cactus to avoid theft [23], Citrus tree for monitoring disease and breeding [24], Cypress for disease monitoring [25] and grapevine for traceability and clonal selection [26] and in roses for digital urban garden management [27].

\section{Role of Rfid in Food Sector}

\section{Shelf life prediction and quality monitoring}

RFID reader and semi active tag integrated with gas sensors were used to assessthe quality of apples by monitoring produced gases such as ethylene [10]. RFID tag integrated with gas sensors (O2 and CO2) was used for checking freshness of Broccoli [28]. Semi-passive RFID loggers wasused for prediction of shelf life of lettuce transported in refrigerated container [29]. It has also been reported that keeping quality of tomatoes and shelf-life of Soybean sprouts and frozen Tilapia fillet was also estimated 
using RFID [7,30,31]. Fish Forecast module integrated with RFID was used for the quality prediction based on the environmental fluctuation information [32]. The basicworking principle and technical characteristics of the RFID technology and also suggestion regarding the vegetable quality traceability was given by Yang and Wang [33].

\section{Cold chain monitoring}

Perishable food products such as vegetables, fruit, meat or fish required refrigeration during transports for safe handling. RFID plays a very important role for supply chain traceability of such agri-food [34-36]. Active and passive RFID loggers are used to find out temperature profile during transport. Therefore, temperature tracking through RFID is done during a commercial shipment of perishable foods [7,37]. Temperaturemanaged traceability system using RFID tag, GPS and mobile communication based on time-temperature theory was developed by Zhang [38]. Many researchers have reported timetemperature indicators for monitoring vegetables from growers to the retail chain using RFID integrated with temperature sensors $[34,35,39]$. Cheese traceability was also assessed by various researcher using RFID tags [40, 41].

\section{Food packaging}

Sensors integrated into food packages could benefit consumers by ensuring freshness and quality while allowing retail industry to more efficiently manage food stocks and product authenticity. Smart radio-frequency labels with sensors are able to measure temperature, humidity and the presence of volatile amine compounds [42]. Controlling temperature and detecting markers of fooddegradation such as carbon dioxide, ethanol and ethylene are allow detecting food degradation and maintaining food quality in packaging [5].

Freshness indicators are monitor the quality of the packaged food by reacting to changes the color of package due to microbial growth or chemical changes in the fresh food product. Freshness indicators can also be used as shelf life prediction for perishable products and considered as the direct indicators of food quality [43]. Integrity indicators indicate any leakage in a package by monitoring the packaging headspace. Biosensors can be placed inside the food package or integrated into the packaging material for the detection of potential molecules such as glucose, organic acids, ethanol, volatile nitrogen compounds, dimethylamine, and trimethylamine, carbon dioxide and sulfuric compounds [44]. Humidity sensors with oxygen-carbon dioxide indicators for seafood products packaging are also being used [3]. Many researchers have developed an "Intelligent Container" with RFID and sensor network for management of logistic processes of perishables fruit and vegetables $[2,45,46]$.

\section{Benefits of rfid}

The RFID system has remarkable benefits over conventional techniques especially over barcodes. Though RFID is not likely to entirely replace commonly used barcodes in the near future but the advantages suggest to additionally apply RFID for added value of identification. RFID tag detection not require human intervention which reduces employment costs and eliminates human errors from data collection. As no line-of-sight is required, tag placement is less constrained and longer read range. Tags can have read/write memory capability while barcodes do not. An RFID tag can store large amounts of data additionally to a unique identifier. Unique item identification is easier to implement and less sensitive to adverse conditions (dust, chemicals, physical damage etc.). Tags can locally store additional information; such distributed data storage may increase fault tolerance of the entire system which reduces inventory control and provisioning costs [47].

RFID benefits in manufacturing processes by providing less manual work, less costs, improving visibility and planning. In warehouse processes, it offers visibility of accurate real-time information, fast locating of products, possibility to record losses, ability to plan product locations strategically. RFID in container management and tracking offers visibility of real-time cargo movement, improves efficiency and increase accuracy. It in distribution processes, accelerates delivery, improves efficiency, increases accuracy and reduces distribution costs.

\section{Conclusion and Future Aspects}

RFID technology combined with the appropriate infrastructure can enable end-to-end traceability in the supply chain at relatively small costs. RFID implementation can assist produce growers to overcome spoilage issues. Using RFID technology, it is possible to monitor temperature and shelf life of perishable items at every stage of the cold chain, and allow both producers and buyers to be notified of custody and conditions of shipments. Competitive pressures, regulatory requirements, a global supply chain, safety concerns in the agrofood sector are overcome by RFID technology. Besides their advantages, some challenges and limitations are also associated with this technology and should be faced in the coming years. RFID operating at harsh environments with dirt and extreme temperatures for a long time duration results huge volume of data that are difficult to manage and needed longer reading frequency ranges due to the reduction of signal strength, behavior of different frequencies, the diversity of the standards and the level of granularity. But with the going on researches, we hope that in the future they will develop some applications which will calculate the gathered data into useful information with the help of special algorithm. Application of RFID will boom in the coming years on account of the advantages like goods identity and logistics tracing at reduced cost, which will surely bring out a revolution in agricultural products logistics and turn to be a new-born economic growth.

\section{References}

1. Wang N, Zhang NQ Wang MH (2006) Wireless sensors in agriculture and food industry - Recent development and future perspective. Comput Electron Agric 50: 1-14. 
2. Ruiz-Garcia L, Lunadei L (2011) The role of RFID in agriculture: Applications, limitations and challenges. Comput Electron Agric 79(1): 42-50.

3. Abad E, Palacio F, Nuin M, Zárate AGD, Juarros A, et al. (2009) RFID smart tag for traceability and cold chain monitoring of foods: demonstration in an intercontinental fresh fish logistic chain. J Food Eng 93(4): 394-399.

4. Want R (2006) An introduction to RFID technology. In IEEE Pervasive computing: Magazine published by the IEEE CS and IEEE Com Soc 5(1) 25-33.

5. Bibi F, Guillaume C, Gontard N, Sorli B (2017) A review: RFID technology having sensing aptitudes for food industry and their contribution to tracking and monitoring of food products.Trends Food Sci Technol 62: 91-103.

6. Aguzzi J, Sbragaglia V, Sarria D, Garcia JA, Costa C, et al. (2011) A new laboratory radio frequency identification (RFID) system for behavioural tracking of marine organisms. Sensors (Basel) 11(10): 9532-9548.

7. Jedermann R, Ruiz-Garcia L, Lang W (2009) Spatial temperature profiling by semi-passive RFID loggers for perishable food transportation. Comput Electron Agric 65(2): 145-154.

8. Todd B, Phillips M, Schultz SM, Hawkins AR, Jensen BD (2009) Lowcost RFID threshold shock sensors. IEEE Sens J 9(4): 464-469.

9. Murkovic' I, Steinberg MD (2009) Radio frequency tag with optoelectronic interface for distributed wireless chemical and biological sensor applications. Sens Actuators B Chem 138(1): 120125.

10. Vergara E, Llobet J, Ramírez L, Ivanov P, Fonseca L, et al. (2007) An RFID reader with on board sensing capability for monitoring fruit quality. Sens Actuators B Chem 127(1): 143-149.

11. Wentworth SM (2003) Microbial sensor tags. In: 2003 IFT (The Institute of Food Engineering) Annual Meeting. Chicago, Illinois, USA.

12. Ampatzidis YG, Vougioukas SG, Bochtis DD (2009) A yield mapping system for hand-harvested fruits based on RFID and GPS location technologies: Field testing. Precis Agric 10: 63-72.

13. Reiners K, Hegger A, Hessel HF, Bock S, Wendl G, et al. (2009) Application of rfid technology using passive hf transponders for the individual identification of weaned piglets at the feed trough. Comput Electron Agric 68(2): 178-184.

14. Chen RS, Chen CC, Yeh KC, Chen YC, Kuo CW (2008) Using RFID technology in food produce traceability. WSEAS Trans Info Sci Appl 5(11): 1551-1560.

15. Samad A, Murdeshwar P, Hameed Z (2010) High-credibility RFIDbased animal data recording system suitable for small-holding rural dairy farmers. Comput Electron Agric 73(2): 213-218.

16. Cai WG, Liang B (2011) Research and implementation of the safety of raw milk traceability management perspective based on RFID technology. Hubei Agricultural Sci 2011-07.

17. Luo Q Xiong B, Geng YL, Pan J (2011) A study on pig slaughter traceability solution based on RFID. Comput Computi Technol Agric 4(346): 710-720.

18. Shougang R, Huanliang X, Lian, Guanghong Z (2010) Research on RFID-based meat product track and traceability system. International Conference on Computer Application and System Modeling (ICCASM), Taiyuan, pp. V8-458-V8-462.

19. Wisanmongkol J, Pongpaibool P (2009) A passive UHF RFID tag for poultry traceability. In: The 2009 International Symposium on Antennas and Propagation, Bangkok, Thailand.

20. Gan W, Zhu Y, Zhang T (2011) On RFID Application in the Tracking and Tracing System of Agricultural Product Logistics. In: Li D, Liu Y, Chen Y
(Eds.), Computer and Computing Technologies in Agriculture IV. CCTA 2010. IFIP Advances in Information and Communication Technology, vol 345. Springer, Berlin, Heidelberg, pp. 400-407.

21. Luvisi A, Panattoni A, Bandinelli R, Rinaldelli E, Pagano M, et al. (2012) Ultra-high frequency transponders in grapevine: a tool for traceability of plants and treatments in viticulture. Biosyst Eng 113: 129-139.

22. Feltham H, Park K, Goulson D (2014) Field realistic doses of pesticide imidacloprid reduce bumblebee pollen foraging efficiency. Ecotoxicol 23(3): 317-323.

23. Associated Press (2008) Theft deterrence for an Arizona icon. New York Times, USA, p.39.

24. Bowman KD (2010) Longevity of radiofrequency identification device microchips in citrus trees. Hort Sci 45(3): 451-452.

25. Miragliotta G, Perego A, Battezzati L (2006) RFID all aprovadeifatti. Wireless 12: 56-62.

26. Bandinelli R,Triolo E, Luvisi A (2009) Employment of radiofrequency technology (RFID) in grapevine nursery traceability. Adv Hort Sci 23(2): 75-80.

27. Luvisi A, Panattoni A, Bandinelli R, Rinaldelli E, Pagano M, et al. (2010) Radiofrequency identification tagging in ornamental shrubs: An application in rose. Hort Technol 20(6): 1037-1042.

28. Eom KH, Kim MC, Lee S, Lee CW (2012) The vegetable freshness monitoring system using RFID with oxygen and carbon dioxide sensor. International Journal of Distributed Sensor Networks 1-6.

29. Jedermann R, Schouten R, Sklorz A, Lang W, Kooten OV (2006) Linking keeping quality models and sensor systems to an autonomous transport supervision system. In: Cold Chain Management - 2nd international Workshop, University Bonn, USA, pp. 3-18.

30. Lee DS, Hwang KJ, An DS, Park JP, Lee HJ (2007) Model on the microbial quality change of seasoned soybean sprouts for on-line shelf life prediction. Int J Food Microbiol 118(3): 285-293.

31. Tingman W, Zhang J, Zhang X (2010) Fish product quality evaluation based on temperature monitoring in cold chain. Afr J Biotechnol 9(37): 6146-6151.

32. Wang L, Kwok SK, Ip WH (2010) A radio frequency identification and sensor based system for the transportation of food. J Food Eng 101(1): 120-129.

33. Yang F, Wang $\mathrm{T}$ (2012) The application of radio frequency identification technology in vegetable quality traceability system. Yantai, International Conference on Systems and Informatics (ICSAI 2012), China.

34. Costa C, Antonucci F, Pallottino F, Aguzzi J, Sarriá D, et al. (2013) A review on agri-food supply chain traceability by means of RFID technology. Food Bioproc Technol 6(2): 353-366.

35. Hu J, Zhang X, Moga LM, Neculita M (2013) Modeling and implementation of the vegetable supply chain traceability system. Food Control 30(1): 341-353.

36. Kumari L, Narsaiah K, Grewal MK, Anurag RK (2015) Application of RFID in Agri-food sector-A review. Trends Food Sci Technol.

37. Amador C, Emond JP, Nascimento Nunes MC (2009) Application of RFID technologies in the temperature mapping of the pineapple supply chain. Sens Instrum Food Qual 3(1): 26-33.

38. Zhang J, Liu L, Mu W, Moga LM, Zhang X (2009) Development of temperature-managed traceability system for frozen and chilled food during storage and transportation. J Food Agric Environ 7(3-4): 132135 .

39. Realini CE, Marcos B (2014) Active and intelligent packaging systems for a modern 872 society. Meat Sci 98(3): 404-419. 
40. Pérez-Aloe R, Valverde JM, Lara A, Carrillo JM, Roa I, et al. (2007) Application of RFID tags for the overall traceability of products in cheese industries. RFID Eurasia 1-5.

41. Papetti P, Costa C, Antonucci F, Figorilli S, Solaini S, et al. (2012) A RFID web-based info tracing system for the artisanal Italian cheese quality traceability. Food Control 27: 234-241.

42. Smits E, Schram J, Nagelkerke M, Kusters R, Heck GV, et al. (2012) Development of printed RFID sensor tags for smart food Packaging. IMCS 2012 - The 14th International Meeting on Chemical Sensors. Pp. 403-406.

43. Galagan Y, Su WF (2008) Fadable ink for time-temperature control of food freshness: Novel new time-temperature indicator. Food Res Int41: 653-657.
44. Vanderroost M, Ragaert P, Devlieghere F, De Meulenaer B (2014) Intelligent food packaging: The next generation. Trends Food Sci Technol 39(1): 47-62.

45. Lang W, Jedermann R, Mrugala D, Jabbari A, Krieg-Brückner B, et al. (2011) The "Intelligent Container"-a cognitive sensor network for transport management. IEEE Sens J 11(3): 688-698.

46. Laniel M, Émond JP (2010) Mapping of RFID tag readability in relation to the food content in a refrigerated sea container at $915 \mathrm{MHz}$. Innov Food Sci Emerging Technol 11(4): 703-706.

47. Kaur M, Sandhu M, Mohan N, Sandhu PS (2011) RFID Technology Principles, Advantages, Limitations \& Its Applications. Int J Comp Electric Eng 3(1): 1793-8163.

\section{Your next submission with Juniper Publishers} will reach you the below assets

- Quality Editorial service

- Swift Peer Review

- Reprints availability

- E-prints Service

- Manuscript Podcast for convenient understanding

- Global attainment for your research

- Manuscript accessibility in different formats ( Pdf, E-pub, Full Text, Audio)

- Unceasing customer service

Track the below URL for one-step submission https://juniperpublishers.com/online-submission.php 